\title{
Evaluasi Kinerja Variansi Frekuensi Lowpass, Bandpass, Highpass dan Bandstop Tapis Chebyshev pada Citra Digital Berderau
}

\author{
Samsumar, L.D. ${ }^{1)}$, Rachman, A.S. ${ }^{2)}$ \\ STMIK Mataram ${ }^{1)}$ \\ Universitas Mataram ${ }^{2)}$ \\ lalu.ellsyam@stmikmataram.ac.id ${ }^{1)}$, asrachman@unram.ac.id ${ }^{1)}$
}

\begin{abstract}
Abstrak - Derau citra digital merupakan permasalahan utama yang sering dihadapi dalam pemrosesan citra karena keberadaan derau pada sebuah file citra dapat menyebabkan kualitas citra terganggu. Oleh karena itu, perlu dilakukan penekanan derau untuk meningkatkan kualitas citra dengan menggunakan tapis Chebyshev. Adapun tujuan dari penelitian ini adalah untuk merestorasi citra dengan menggunakan tapis chebyshev pada empat bidang pelewatan frekuensi (low pass, bandpass, highpass, dan bandstop).

Hasil penelitian menunjukkan bahwa citra yang diuji pada masing-masing frekuensi menunjukkan perbedaan nilai evaluasi kinerja yang signifikan, dimana citra terbaik untuk penapisan frekuensi cut-off lowpass dihasilkan pada frekuensi $50 \mathrm{~Hz}$ melalui derau Gaussian dengan nilai rasio RMSE sebesar 0.4669, citra terbaik untuk penapisan frekuensi cut-off bandpass dihasilkan pada frekuensi $1000 \mid 1500 \mathrm{~Hz}$ melalui derau Gaussian dengan nilai rasio RMSE sebesar 0.0292, citra terbaik untuk penapisan frekuensi cut-off highpass dihasilkan pada frekuensi $1000 \mathrm{~Hz}$ melalui derau Gaussian dengan nilai rasio RMSE sebesar 0.0293, dan citra terbaik untuk penapisan frekuensi cut-off bandstop dihasilkan pada frekuensi $50 \mid 100 \mathrm{~Hz}$ melalui derau Gaussian dengan nilai rasio RMSE sebesar 0.4231.
\end{abstract}

Kata kunci: derau, tapis Chebyshev, lowpass, bandpass, highpass, bandstop

\section{Latar Belakang}

Restorasi citra memegang peranan penting dalam pengolahan citra digital guna mendapatkan citra yang lebih baik. Proses restorasi citra ditujukan agar derau yang terdapat pada citra menjadi lebih tertekan sehingga informasi yang terdapat pada citra menjadi lebih jelas. Derau yang terdapat pada sebuah citra bisa disebabkan oleh proses akuisisi, transmisi, dan kompresi.

Penekanan derau pada sebuah citra digital merupakan langkah awal atau pra-pengolahan yang harus dilakukan dalam pengolahan citra digital. Hal ini ditujukan agar derau yang terdapat pada citra menjadi tertekan dan informasi yang akan diolah lebih lanjut menjadi lebih baik. Ada beberapa jenis tipe derau yang sering dijumpai pada citra digital yakni derau Gaussian, derau Poisson, derau Salt \& Papper, derau Speckle dan lain sebagainya. Derau yang terdapat pada sebuah data atau informasi memiliki watak acak. Hal ini berarti bahwa derau tersebar pada seluruh bagian data. Karena wataknya yang acak maka derau tidak bisa dihilangkan melainkan hanya bisa ditekan.

Untuk menekan derau yang terdapat pada sebuah citra digital maka diperlukan sebuah metode penapisan yang mampu menekan derau yang tersebar di seluruh piksel. Beberapa metode penapisan yang sering digunakan untuk menekan derau pada citra diantaranya adalah tapis Rerata, tapis Median, tapis Gaussian, tapis unsharp, dan lain sebagainya. Seiring dengan berkembangnya ilmu pengolahan sinyal dan citra digital, para peneliti telah mengembangkan banyak sekali metode penapisan yang mampu menekan derau secara optimal.

Salah satu metode penapisan yang sering digunakan dalam pengolahan sinyal digital yaitu tapis Chebyshev. Tapis ini memiliki kelebihan yaitu memiliki transisi yang lebih tajam dan ripples pada bidang bandpass dan bandstop yang lebih kecil.

Pada makalah ini dilakukan penelitian tentang "Penapisan Citra berbasis Tapis Chebyshev pada Domain Frekuensi Lowpass, Bandpass, Highpass dan Bandstop".

\section{Tinjauan Pustaka}

a. Citra Digital

Citra digital dapat didefinisikan sebagai fungsi dua variabel, $f(x, y)$, dimana $x$ dan $y$ adalah koordinat spasial dan nilai $f(x, y)$ adalah intensitas citra pada koordinat tersebut, hal tersebut diilustrasikan pada Gambar 1. Teknologi dasar untuk menciptakan dan menampilkan warna pada citra digital berdasarkan pada penelitian bahwa sebuah warna merupakan kombinasi dari tiga warna dasar, yaitu merah, hijau, dan biru (Red, 
Green, Blue). Komposisi warna RGB tersebut dapat dijelaskan pada Gambar 2.

Sebuah citra diubah ke bentuk digital agar dapat disimpan dalam memori komputer atau media lain. Proses mengubah citra ke bentuk digital bisa dilakukan dengan beberapa perangkat, misalnya scanner, kamera digital, dan handycam.

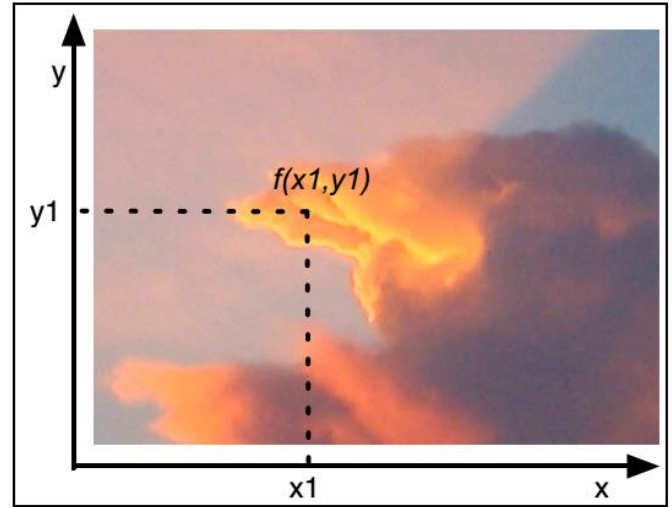

Gambar 1 Citra digital (Nhielma, 2008)

Ketika sebuah citra sudah diubah ke dalam bentuk digital (selanjutnya disebut citra digital), bermacam-macam proses pengolahan citra dapat diperlakukan terhadap citra tersebut.

Pengolahan citra digital dapat dilakukan dengan cara-cara sebagai berikut:

- Representasi dan permodelan citra

- Peningkatan kualitas citra

- Restorasi citra

- Analisis citra

- Rekonstruksi citra

- Kompresi citra

Dalam makalah ini, pengolahan citra digital difokuskan pada teknik penapisan citra menggunakan tapis Chebyshev.

\section{b. Tapis Digital}

Tapis digital merupakan suatu tapis elektronik yang bekerja dengan menerapkan operasi matematika digital atau algoritma pada suatu pemrosesan sinyal. Salah satu batasan utama pada tapis digital adalah dalam hal keterbatasan kecepatan pemrosesan atau waktu komputasi yang sangat tergantung dengan kemampuan mikrokontroler atau komputer yang digunakan.

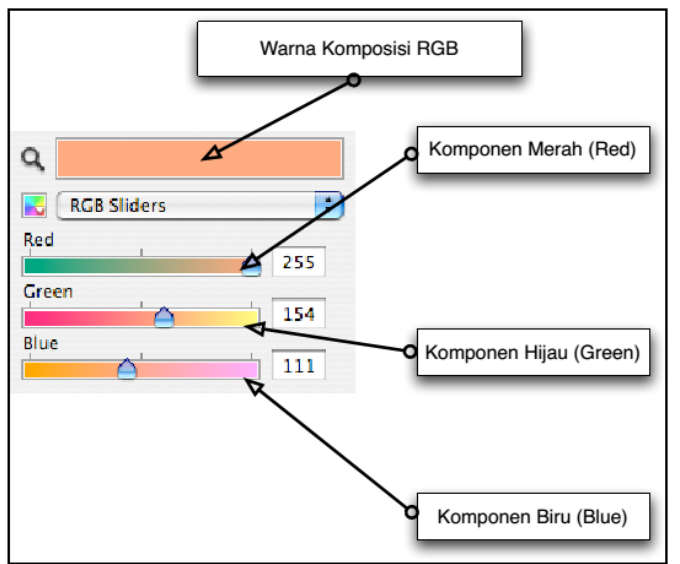

Gambar 2 Komposisi warna RGB (Nhielma, 2008)

Ada beberapa macam klasifikasi tapis yaitu:

1. Berdasarkan sinyal yang ditapis yaitu, Tapis Analog dan Tapis Digital.

2. Berdasarkan respons frekuensi yaitu, LPF (low pass filter), HPF (high pass filter), PF(band pass filter), BSF(band stop filter).

3. Berdasarkan bentuk respon frekuensi yaitu, Hamming, Kaiser, Firls, Blackman dan Fir2.

4. Berdasarkan respon implusnya yaitu, FIR (Finite Impulse Response) dan IIR (infinite Impulse Response).

\section{c. Tapis Chebyshev}

Chebyshev, matematikawan Rusia, tahun 1899 menggunakan suatu fungsi (kemudian disebut fungsi Chebyshev) dalam mempelajari konstruksi mesin uap. Tapis Chebyshev memperlihatkan respon berbentuk equiripple di daerah bandpass dan menurun secara monoton di daerah bandstop. Bentuk ripple filter Chebyshev dibedakan atas dasar ganjil atau genap orde tapisnya. Tapis berorde ganjil memiliki penguatan magnituda sama dengan 1 pada $\omega=0$, sedangkan untuk orde genap memiliki deviasi magnituda maksimum untuk $\omega=0$. Jumlah total maksima dan minima di daerah passband sama dengan orde tapisnya (N). Semua zero transmisi dari tapis Chebyshev terletak di $\omega=\infty$, sehingga menghasilkan tipe all-pole filter. Respon tapis Chebyshev.

Berikut adalah persamaan tapis Chebyshev (Asep, 2009):

$$
|T(j \omega)|=\frac{1}{\sqrt{1+\varepsilon^{2} \cos ^{2}\left(N \cos ^{-1}\left(\frac{\omega}{\omega_{p}}\right)\right)}}, \quad \omega \leq \omega_{p}
$$

Kutub-kutub pada tapis Chebyshev adalah:

$$
p_{k}=\operatorname{Re}\left\{p_{k}\right\}+j \operatorname{Im}\left\{p_{k}\right\}
$$


dengan,

$$
\begin{aligned}
& \operatorname{Re}\left\{p_{k}\right\}=-\omega_{p} \sin \left(\left\{\frac{2 k-1}{N}\right\} \frac{\pi}{2}\right) \sinh \left(\frac{1}{N} \sinh ^{-1} \frac{1}{\varepsilon}\right) \\
& \operatorname{Im}\left\{p_{k}\right\}=\omega_{p} \cos \left(\left\{\frac{2 k-1}{N}\right\} \frac{\pi}{2}\right) \cosh \left(\frac{1}{N} \sinh ^{-1} \frac{1}{\varepsilon}\right)
\end{aligned}
$$

Fungsi alih tapis Chebyshev didefinisikan:

$$
T(s)=\frac{K \omega_{p}^{N}}{\varepsilon \times 2^{N-1} \times\left(s-p_{1}\right)\left(s-p_{2}\right) \cdots\left(s-p_{N}\right)}
$$

\section{c. Derau}

Derau atau dalam bahasa Inggris disebut dengan "noise" adalah sinyal-sinyal yang tidak diinginkan dalam suatu sistem komunikasi atau informasi. Sinyal-sinyal derau ini dapat mengganggu kualitas penerimaan sinyal dan reproduksi sinyal yang akan dipancarkan. Derau juga dapat membatasi jangkauan sistem pada daya pancaran tertentu, mempengaruhi sensitivitas atau kepekaan sinyal penerimaan dan bahkan akan mengakibatkan pengurangan bandwidth pada suatu sistem.

Ada banyak jenis derau yang dapat mempengaruhi kualitas citra, diantaranya adalah salt and Pepper, Gaussian, Speckle, Localvar, dan Poisson. Efek masing-masing noise tentunya berbeda-beda. Ada yang efeknya sangat mempengaruhi tampilan citra, tapi ada juga yang tidak begitu berpengaruh terhadap citra.

\section{d. RMSE}

Kualitas citra merupakan karakteristik dari sebuah citra yang berupa ukuran degradasi citra. Kualitas citra diukur dengan RMSE (root mean squared error). RMSE digunakan untuk mengukur tingkat error pada citra hasil penapisan dengan cara membandingkannya dengan citra original. Untuk $f^{\prime}(x, y)$ adalah piksel citra hasil penapisan, $f(x, y)$ adalah piksel citra original, $m$ adalah panjang citra dan $\mathrm{n}$ adalah lebar citra, RMSE dihitung dengan persamaan sebagai berikut:

$$
R M S E \sqrt{\frac{1}{m \times n} \sum_{x=1}^{M} \sum_{y=1}^{N}\left(f(x, y)-f^{\prime}(x, y)\right)^{2}}
$$

Semakin besar nilai RMSE, maka citra hasil filtering tersebut memiliki tingkat error yang semakin besar, sehingga citra yang dihasilkan semakin tidak mirip dengan citra original, begitupun sebaliknya.

\section{Metodologi Penelitian}

Adapun metodologi yang dilakukan dalam pengerjaan sistem adalah sebagai berikut:

1. Mengekstraksi citra uji dengan membaca tiap intensitas piksel.

2. Menerapkan teknik penapisan Chebyshev pada berbagai bidang frekuensi (lowpass, bandpass, highpass, dan bandstop).

3. Melakukan uji coba terhadap beberapa citra uji, dengan menyisipkan derau gaussian pada citra-citra uji.

4. Melakukan tabulasi hasil dengan membandingkan kriteria evaluasi berdasarkan nilai parameter RMSE (Root Mean Squared Error) dari hasil penapisan yang dilakukan.

Adapun rancangan antarmuka dari program atau sistem yang dibangun pada penelitian ini diperlihatkan Gambar 3.

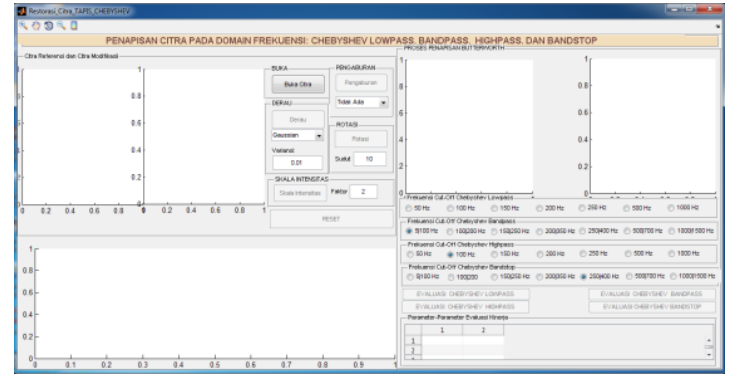

Gambar 3 Antarmuka Program

Pada antarmuka yang dirancang, disediakan beberapa tombol untuk membaca citra, melakukan pengaburan, menambahkan derau, melakukan rotasi dan mengubah skala intensitas citra. Citra semula dan citra yang telah dimodifikasi kemudian ditampilkan pada kedua sumbu yang telah disediakan. Pada antarmuka yang dirancang, juga disediakan empat panel, yang masing-masing memuat tombol untuk menetapkan frekuensi cut-off untuk tiap bidang frekuensi penapisan. Tombol $5 \mid 100 \mathrm{~Hz}$ pada panel Frekuensi cut-off Chebyshev Bandpass menyatakan bahwa frekuensi cutoff kiri adalah 5 $\mathrm{Hz}$ dan frekuensi cutoff kanan adalah $100 \mathrm{~Hz}$. Tombol $100 \mid 200 \mathrm{~Hz}$ pada panel Frekuensi Cut-Off Chebyshev Bandstop menyatakan bahwa frekuensi cut-off kiri adalah $100 \mathrm{~Hz}$ dan frekuensi cut-off kanan adalah $200 \mathrm{~Hz}$.

Setiap bidang penapisan frekuensi disediakan tombol evaluasi, yang berguna untuk menampilkan tabel dan grafik dari parameter RMSE (Root Mean Squared Error).

Pada tampilan antarmuka program terdapat beberapa kontrol yang merepresentasikan setiap langkah untuk melakukan penapisan citra menggunakan tapis Eliptik pada bidang frekuensi lowpass, highpass, bandpass dan bandstop. 


\section{Pengujian Parameter RMSE Program (Root Mean Square Error)}

Berikut adalah proses penapisan eliptik lowpass, bandpass, highpass, dan bandstop terhadap citra lenna.png dengan frekuensi cut-off $50 \mathrm{~Hz}$ sampai dengan $1000 \mathrm{~Hz}$. Pada uji coba ini, citra lenna.png menggunakan jenis derau Gaussian dengan variansi 0.01 untuk masingmasing frekuensi. Sedangkan, faktor skala intensitas yang digunakan adalah sebesar 2 dan rotasi yang digunakan adalah sebesar 10. Dalam penelitian ini juga digunakan lima jenis variasi pengaburan untuk masing-masing frekuensi, antara lain; tanpa pengaburan, pengaburan Rerata, Motion, Disk, dan Gaussian. Dari hasil pengujian yang dilakukan di atas, terlihat bahwa tapis eliptik lowpass, bandpass, highpass, dan bandstop dengan frekuensi cut-off $50 \mathrm{~Hz}$ sampai $1000 \mathrm{~Hz}$ menghasilkan citra dengan derau tereduksi yang berbeda-beda untuk setiap jenis pengaburan.

\section{a. Pengujian RMSE: Citra Uji "boat" dengan Derau Gaussian Variansi 0.01}

Gambar 4 menunjukkan grafik batang dari parameter RMSE atas citra uji boat berderau yang ditapis lowpass pada sejumlah bidang frekuensi. Dapat diperhatikan bahwa rasio RMSE terkecil sebesar 0.4669 didapatkan dari penapisan lowpass dengan frekuensi cutoff 50 $\mathrm{Hz}$. Nilai rasio RMSE terbesar sebesar 0.4714 dari penapisan lowpass dengan frekuensi cutoff $1000 \mathrm{~Hz}$. Nilai-nilai rasio RMSE yang didapatkan dari penapisan lowpass pada sejumlah bidang frekuensi tidak memiliki selisih yang jauh.

Gambar 5 menunjukkan grafik batang dari parameter RMSE atas citra uji boat berderau yang ditapis bandpass pada sejumlah bidang frekuensi.

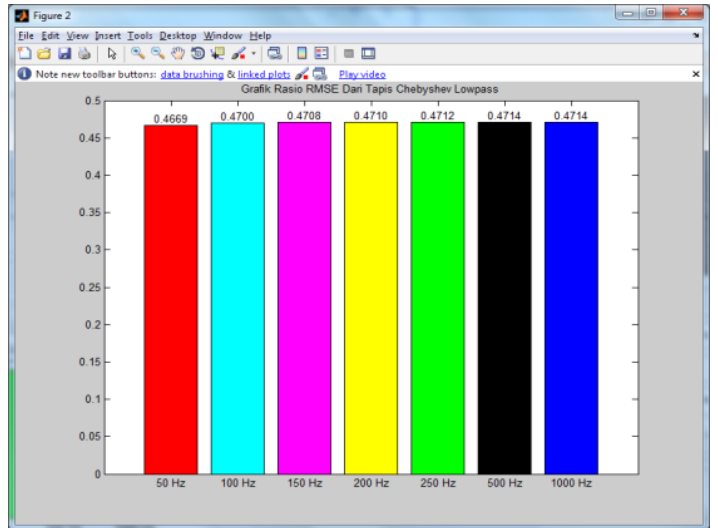

Gambar 4 Grafik batang rasio RMSE atas citra uji "boat" berderau dengan variansi 0.01 yang ditapis lowpass pada sejumlah bidang frekuensi

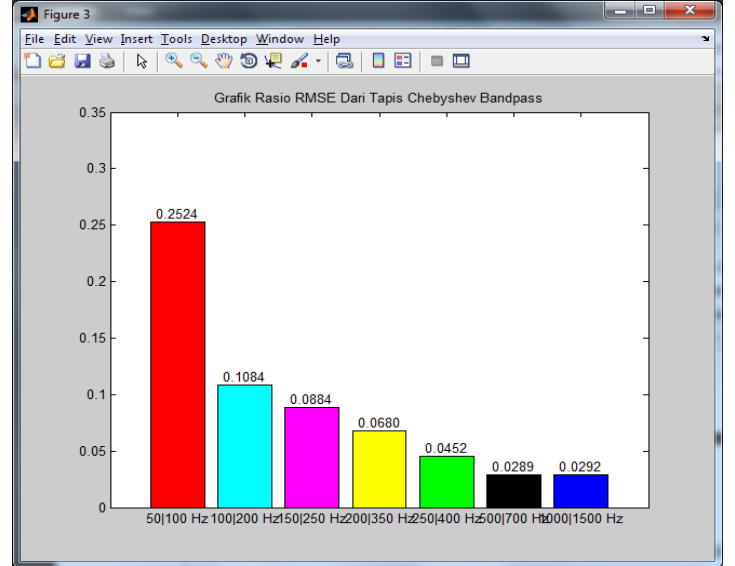

Gambar 5 Grafik batang RMSE atas citra uji "boat" berderau dengan variansi 0.01 yang ditapis bandpass pada sejumlah bidang frekuensi

Dapat diperhatikan bahwa rasio RMSE terkecil sebesar 0.0292 didapatkan dari penapisan bandpass dengan frekuensi cut-off $1000 \mid 1500 \mathrm{~Hz}$. Nilai rasio RMSE terbesar sebesar 0.2524 dari penapisan bandpass dengan frekuensi cut-off $50 \mid 100 \mathrm{~Hz}$.

Gambar 6 menunjukkan grafik batang dari parameter RMSE atas citra uji boat berderau yang ditapis highpass pada sejumlah bidang frekuensi. Dapat diperhatikan bahwa nilai rasio RMSE terkecil sebesar 0.0293 didapatkan dari penapisan highpass dengan frekuensi cutoff $1000 \mathrm{~Hz}$. Nilai rasio RMSE terbesar sebesar 0.1527 dari penapisan highpass dengan frekuensi cutoff $50 \mathrm{~Hz}$. Nilai rasio RMSE yang didapatkan dari penapisan highpass pada sejumlah bidang frekuensi memiliki selisih yang jauh, dengan kecenderungan mengecil secara eksponensial dengan bertambahnya frekuensi cut-off.

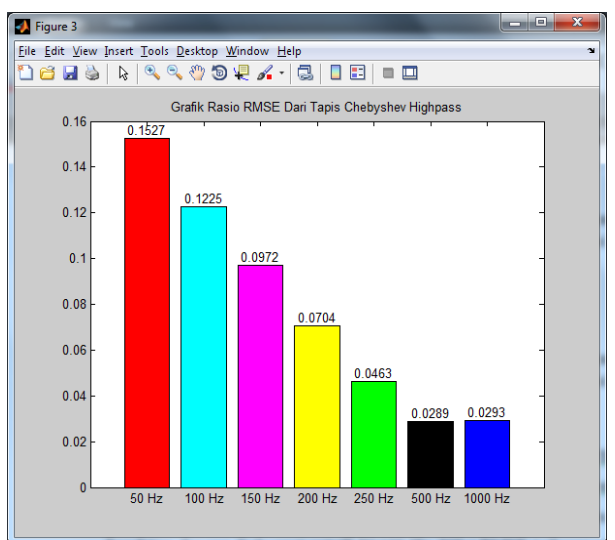

Gambar 6 Grafik batang RMSE atas citra uji "boat" berderau dengan variansi 0.01 yang ditapis highpass pada sejumlah bidang frekuensi 


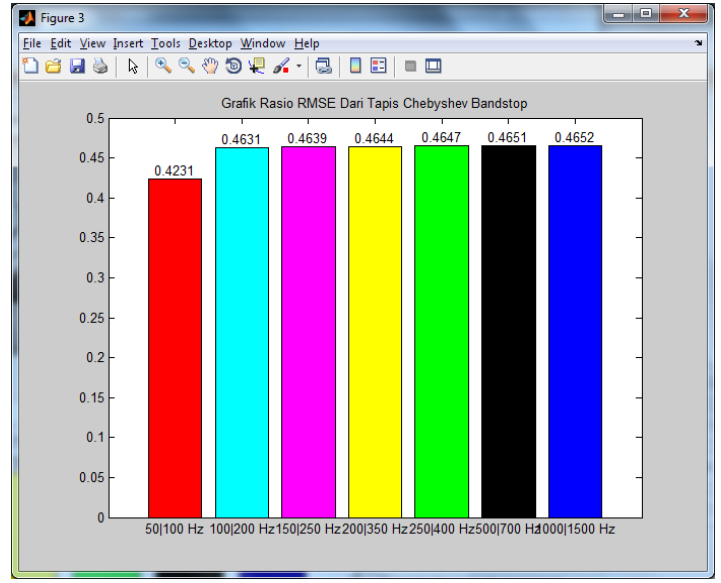

Gambar 7 Grafik batang RMSE atas citra uji "boat" berderau dengan variansi 0.01 yang ditapis bandstop pada sejumlah bidang frekuensi

Gambar 7 menunjukkan grafik batang dari parameter RMSE atas citra uji boat berderau yang ditapis bandstop pada sejumlah bidang frekuensi. Dapat diperhatikan bahwa nilai rasio RMSE terkecil sebesar 0.4231 didapatkan dari penapisan bandstop dengan frekuensi cut-off $50 \mid 100 \mathrm{~Hz}$. Nilai rasio RMSE terbesar sebesar 0.4652 dari penapisan bandstop dengan frekuensi cut-off $1000 \mid 1500 \mathrm{~Hz}$. Nilai-nilai RMSE yang didapatkan dari penapisan bandstop pada sejumlah bidang frekuensi tidak memiliki selisih yang jauh, yang ditunjukkan dengan grafik batang yang cenderung datar.

\section{Pengujian RMSE: Citra Uji "lena" dengan Derau Gaussian Variansi 0.01}

Gambar 8 menunjukkan grafik batang dari parameter RMSE atas citra uji lena berderau yang ditapis lowpass pada sejumlah bidang frekuensi. Dapat diperhatikan bahwa rasio RMSE terkecil sebesar 0.39938 didapatkan dari penapisan lowpass dengan frekuensi cutoff $50 \mathrm{~Hz}$. Nilai rasio RMSE terbesar sebesar 0.3985 dari penapisan lowpass dengan frekuensi cut-off $1000 \mathrm{~Hz}$. Nilainilai RMSE yang didapatkan dari penapisan lowpass pada sejumlah bidang frekuensi tidak memiliki selisih yang jauh.

Gambar 9 menunjukkan grafik batang dari parameter RMSE atas citra uji boat berderau yang ditapis bandpass pada sejumlah bidang frekuensi. Dapat diperhatikan bahwa rasio RMSE terkecil sebesar 0.0249 didapatkan dari penapisan bandpass dengan frekuensi cutoff $1000 \mid 1500 \mathrm{~Hz}$. Nilai rasio RMSE terbesar sebesar 0.2341 dari penapisan bandpass dengan frekuensi cut-off $50 \mid 100 \mathrm{~Hz}$.

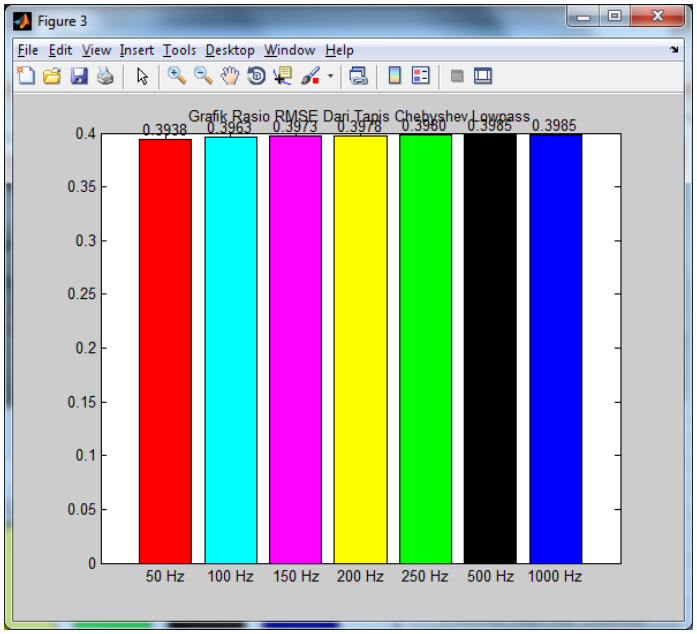

Gambar 8 Grafik batang RMSE atas citra uji "lena" berderau dengan variansi 0.01 yang ditapis lowpass pada sejumlah bidang frekuensi

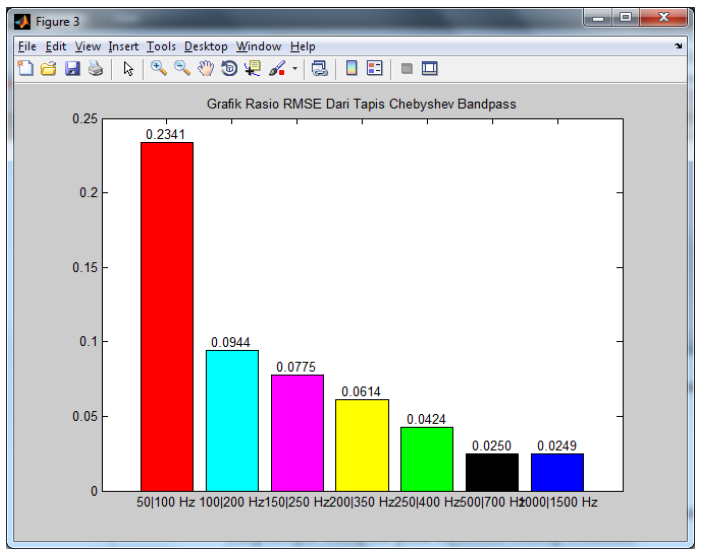

Gambar 9 Grafik batang RMSE atas citra uji lena berderau dengan variansi 0.01 yang ditapis bandpass pada sejumlah bidang frekuensi

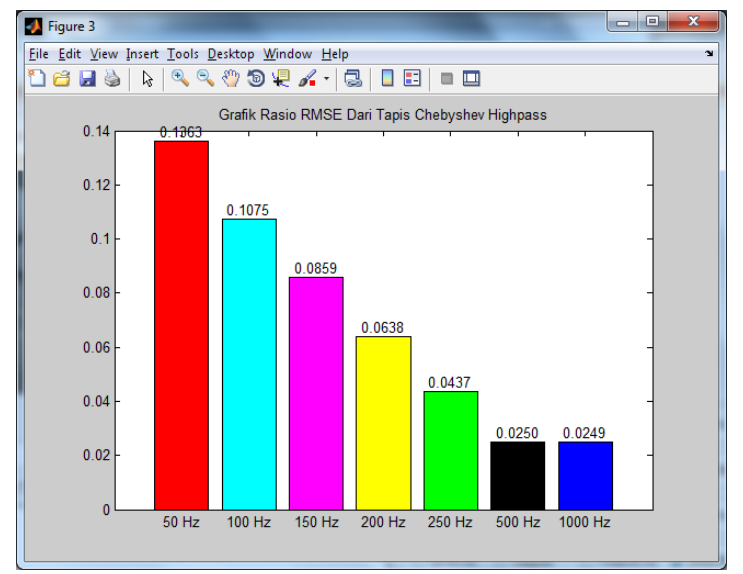

Gambar 10 Grafik batang RMSE atas citra uji "lena" berderau dengan variansi 0.01 yang ditapis highpass pada sejumlah bidang frekuensi 


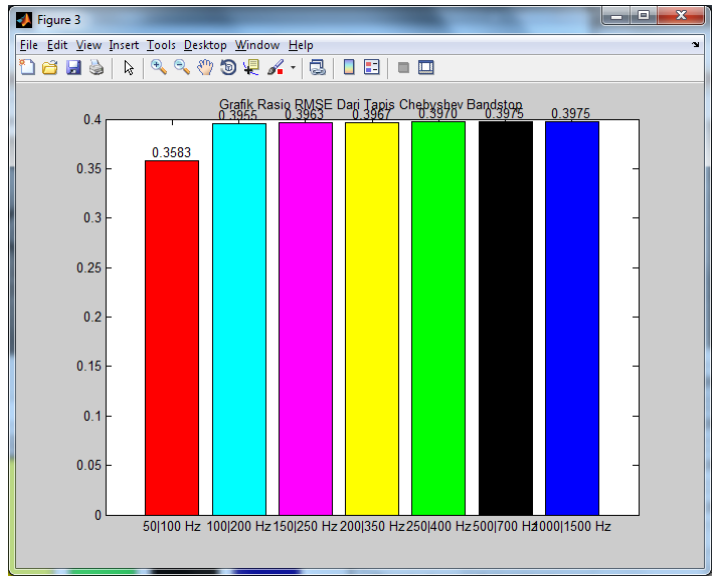

Gambar 11 Grafik batang RMSE atas citra uji "lena" berderau dengan variansi 0.01 yang ditapis bandstop pada sejumlah bidang frekuensi
Gambar 10 menunjukkan grafik batang dari parameter RMSE atas citra uji lena berderau yang ditapis bandpass pada sejumlah bidang frekuensi. Dapat diperhatikan bahwa nilai rasio RMSE terkecil sebesar 0.0249 didapatkan dari penapisan bandpass dengan frekuensi cutoff $1000 \mid 1500 \mathrm{~Hz}$.

Nilai RMSE terbesar sebesar 0.1263 dari penapisan bandpass dengan frekuensi cut-off $50 \mid 100 \mathrm{~Hz}$. Nilai-nilai rasio RMSE yang didapatkan dari penapisan bandpass pada sejumlah bidang frekuensi memiliki selisih yang jauh, dengan kecenderungan mengecil secara eksponensial dengan bertambahnya frekuensi cutoff.

Gambar 11 menunjukkan grafik batang dari parameter RMSE atas citra uji boat berderau yang ditapis bandstop pada sejumlah bidang frekuensi. Dapat diperhatikan bahwa nilai rasio RMSE terkecil sebesar 0.3583 didapatkan dari penapisan bandstop dengan frekuensi cutoff $50 \mid 100 \mathrm{~Hz}$.

Nilai rasio RMSE terbesar sebesar 0.3975 dari penapisan bandstop dengan frekuensi cut-off 1000|1500 Hz. Nilai-nilai RMSE yang didapatkan dari penapisan bandstop pada sejumlah bidang frekuensi tidak memiliki selisih yang jauh, yang ditunjukkan dengan grafik batang yang cenderung datar.

\section{c. Pengujian RMSE: Citra Uji "cameraman" dengan Derau Gaussian Variansi 0.01}

Gambar 12 menunjukkan grafik batang dari parameter RMSE atas citra uji cameraman berderau yang ditapis lowpass pada sejumlah bidang frekuensi. Dapat diperhatikan bahwa rasio
RMSE terkecil sebesar 0.4664 didapatkan dari penapisan lowpass dengan frekuensi cutoff 50 Hz. Nilai rasio RMSE terbesar sebesar 0.4709 dengan frekuensi cutoff $1000 \mathrm{~Hz}$.

Dari penapisan lowpass pada sejumlah bidang frekuensi tidak memiliki selisih yang jauh.

Gambar 13 menunjukkan grafik batang dari parameter RMSE atas citra uji cameraman berderau yang ditapis bandpass pada sejumlah bidang frekuensi. Dapat diperhatikan bahwa nilai rasio RMSE terkecil sebesar 0.0297 didapatkan dari penapisan bandpass dengan frekuensi cutoff $1000 \mid 1500 \mathrm{~Hz}$.

Nilai rasio RMSE terbesar sebesar 0.2718 dari penapisan bandpass dengan frekuensi cut-off $50 \mid 100 \mathrm{~Hz}$. Nilai-nilai RMSE yang didapatkan dari penapisan bandpass pada sejumlah bidang frekuensi memiliki selisih yang jauh, dengan kecenderungan mengecil secara eksponensial dengan bertambahnya frekuensi cut-off.

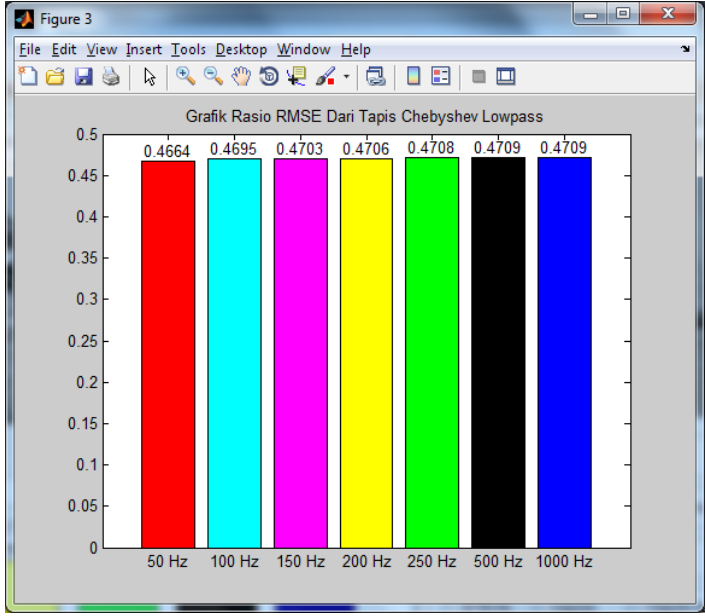

Gambar 12 Grafik batang RMSE atas citra uji "cameraman" berderau dengan variansi 0.01 yang ditapis lowpass pada sejumlah bidang frekuensi

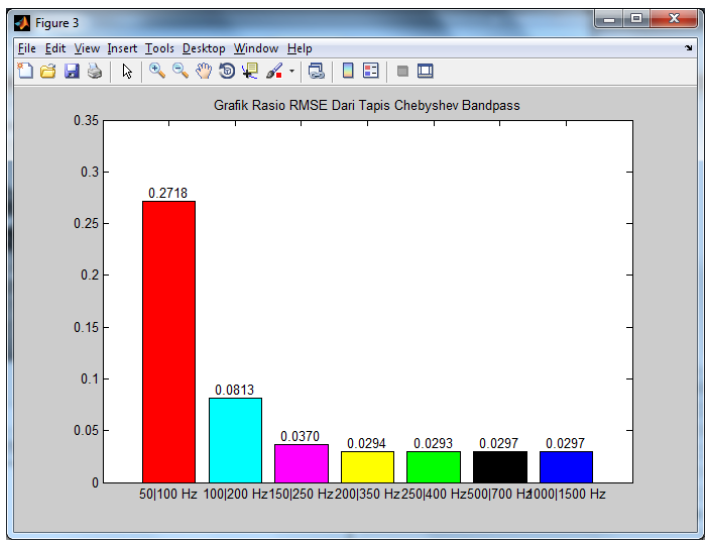

Gambar 13 Grafik batang RMSE atas citra uji "cameraman" berderau dengan variansi 0.01 yang ditapis bandpass pada sejumlah bidang frekuensi 


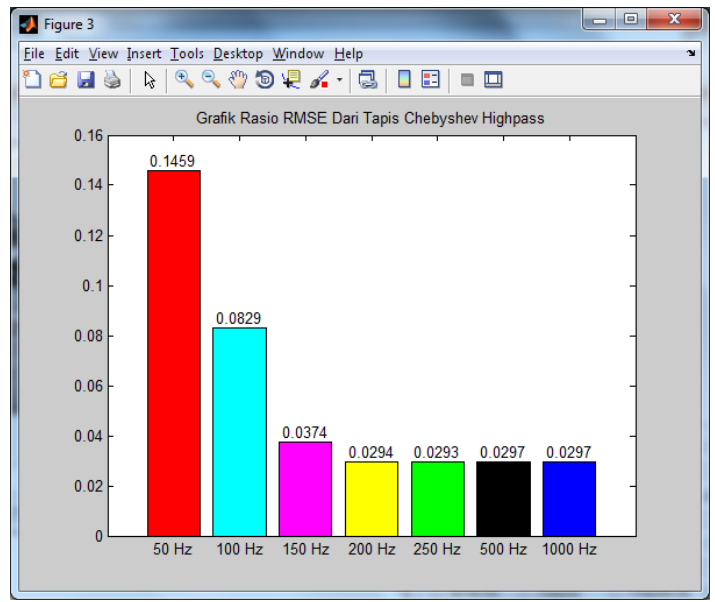

Gambar 14 Grafik batang RMSE atas citra uji "cameraman" berderau dengan variansi 0.01 yang ditapis highpass pada sejumlah bidang frekuensi

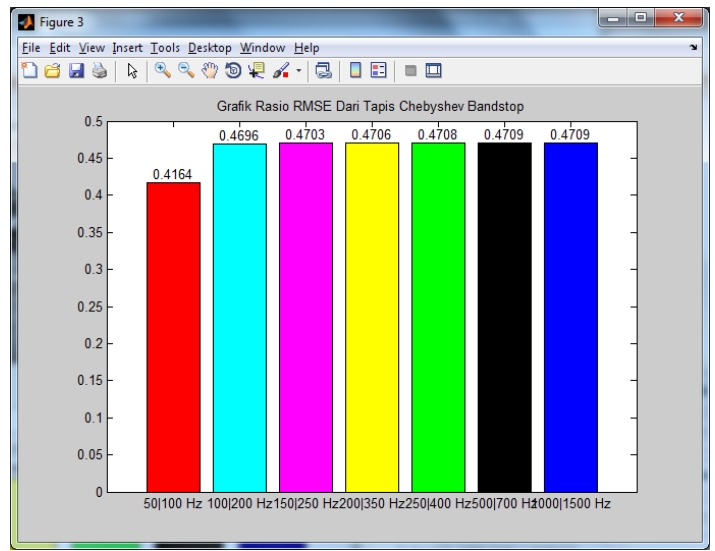

Gambar 15 Grafik batang RMSE atas citra uji "cameraman" berderau dengan variansi 0.01 yang ditapis bandstop pada sejumlah bidang frekuensi

Gambar 14 menunjukkan grafik batang dari parameter RMSE atas citra uji cameraman berderau yang ditapis highpass pada sejumlah bidang frekuensi. Dapat diperhatikan bahwa nilai RMSE terkecil sebesar 0.1459 didapatkan dari penapisan highpass dengan frekuensi cutoff 1000 Hz. Nilai RMSE terbesar sebesar 0.0297 dari penapisan highpass dengan frekuensi cutoff 50 $\mathrm{Hz}$. Nilai-nilai RMSE yang didapatkan dari penapisan highpass pada sejumlah bidang frekuensi memiliki selisih yang jauh, dengan kecenderungan mengecil secara eksponensial dengan bertambahnya frekuensi cut-off.

Gambar 15 menunjukkan grafik batang dari parameter RMSE atas citra uji boat berderau yang ditapis bandstop pada sejumlah bidang frekuensi. Dapat diperhatikan bahwa nilai RMSE terkecil sebesar 0.4164 didapatkan dari penapisan bandstop dengan frekuensi cut-off
$50 \mid 100 \mathrm{~Hz}$. Nilai RMSE terbesar sebesar 0.4709 dari penapisan bandstop dengan frekuensi cut-off $1000 \mid 1500 \mathrm{~Hz}$. Nilai-nilai RMSE yang didapatkan dari penapisan bandstop pada sejumlah bidang frekuensi tidak memiliki selisih yang jauh, yang ditunjukkan dengan grafik batang yang cenderung datar.

\section{Kesimpulan dan Saran \\ a. Kesimpulan}

Dari analisa dan pengujian yang telah dilakukan, beberapa kesimpulan dapat ditarik sebagai berikut:

1. Koefisien-koefisien frekuensi dari ketiga citra uji yang dikaji (boat, lena, dan cameraman) terkonsentrasi di pusat bidang frekuensi atau pada bidang frekuensi rendah. Koefisienkoefisien frekuensi dari derau Gaussian yang diberikan tersebar ke seluruh bidang frekuensi.

2. Penapisan tapis chebyshev pada citra uji berderau menghasilkan nilai RMSE berbeda, tergantung dari jenis bidang frekuensi penapisan (lowpass, highpass, bandpass, atau bandstop) dan frekuensi cutoff yang diberikan.

3. Penapisan chebyshev pada bidang frekuensi penapisan bandpass dan highpass menghasilkan nilai-nilai RMSE yang jauh lebih kecil daripada bidang frekuensi penapisan lowpass dan bandstop. Nilai-nilai RMSE bidang frekuensi penapisan bandpass dan highpass menyusut secara eksponensial ketika frekuensi cutoff bertambah. Nilai-nilai RMSE bidang frekuensi penapisan lowpass dan bandpass cenderung sama ketika frekuensi cutoff bertambah.

\section{b. Saran}

Penelitian lebih lanjut dapat dilakukan dengan mengkaji jenis derau lain seperti derau Salt \& Pepper atau derau Speckle.

\section{Pustaka}

Asep Najmurrokhman. 2009. Filter Butterworth dan Chebyshev. Universitas Jendral Ahmad Yani

Gaikwad, K. dan Chavan, M. 2016. Design and Implementation Digial Chebyshev Type II Filter Using XSG for Noise Reduction ECG Signal, International Journal of Engineering Research and Application, SSN : 2248-9622, Vol. 6, Issue 6, ( Part -5).

McAndrew, A. 2004. An Introduction to Digital Image Processing with Matlab. Victoria University of Technology. 
Nhielma. 2008. "Teori Dasar Pengolahan Citra". https://nhielma.wordpress.com/2008/11/25/teor i-dasar-pengolahan-citra.

(Diakses pada tanggal 09 Oktober 2017).

Tian D, A. Knyazev, H. Mansour, dan A. Vetro. 2014. Chebyshev and Conjugate Gradient Filters for Graphs Image Denoising, Mitsubishi Electric Research Laboratories. 